\title{
Incorporating a Metacognitive Learning Model to Improve Geometric Thinking in High-School Students
}

\author{
Erez Nahmias ${ }^{1} \&$ Mina Teicher ${ }^{1}$ \\ ${ }^{1}$ Department of Mathematics, Bar Ilan University, Israel \\ Correspondence: Erez Nahmias, Department of Mathematics, Bar Ilan University, Israel. E-mail: \\ 555nsih@gmail.com
}

Received: February 5, 2021

Accepted: March 10, $2021 \quad$ Online Published: August 30, 2021

doi:10.5539/jel.v10n5p102

URL: https://doi.org/10.5539/jel.v10n5p102

\begin{abstract}
Thinking development processes among high-school students is an important and significant issue that has been widely investigated (Leviathan, 2012; Ball, 1996; De Risi, 2015). A few studies discuss the development of mathematical thinking as this field contains additional difficulties to the traditional factors, teachers, students, and parents, and is one of the most important areas taught in school, according to De Risi (2015). Due to the importance of this subject, the challenge facing researchers, mathematicians, and educators is how to improve students' abilities and achievements in mathematics. In recent years, researchers have found that in order to improve students' achievements and abilities in mathematics, one can use self-direction. Self-direction is a strategy by which the learner acquires the ability to cope with learning from several aspects and contributes to inking development. In this study, we showed that self-directed learning with an emphasis on metacognition would improve students' understanding of the subject in question. Using the metacognitive guidance model, the students acquire and develop learning skills that contribute to developing their geometric thinking. In this study, there is the added value of using a learning model based on metacognitive guidance and its significant contribution to combining multiple subjects into one problem.
\end{abstract}

Keywords: self-directed learning, metacognition, geometric learning, metacognitive guidance

\section{Introduction}

In the last few decades, mathematics is considered one of the most impotent subjects taught in school by many researchers (Paul, Gregory, Elizabeth, \& Karen, 2015).

Due to the importance of the subject, many studies have shown how to improve students' abilities and achievements in various subjects in mathematics (Kramarski \& Revach, 2009). It has been found by Perry, Phillips and Hutchinson (2006) that to improve students' achievements and ability to solve complex problems, one should first improve thestudents' thinking ability.

Thinking is defined as an activity in which information is absorbed from the environment by the senses or extracted from memory and undergoes processing and reorganization in the brain (Putnam, 1992; Pintrich, 2000). In the theory of pedagogy, there have been several notable changes; the main one is students' encouragement to think (Putnam, 1992; Pintrich, 2000). In this paperis paper's scope, we refer to the broader aspect of thinking, not only performing an algorithm. Thinking includes reflective thinking that will encourage discussion and raising questions as a means of advancing the goal as well.

Teaching with the encouragement of thinking gives students tools to conduct comprehensive research on their topic. The scope of the knowledge a student acquires expands while investigating a topic via asking related questions and searching for answers similar to academic scholars (Zimmerman, 1990). This is called a student as a researcher. Accordingly, the student as a researcher approach is shown to be extremely useful in the mathematics pedagogy to develop mathematical and geometric abilities. Such a student will be provided with learning tools and skills that will develop his sense of ability, curiosity, integration of knowledge, development of proof, logic, and integration of various mathematics fields.

As is known, a student in an education system studies multiple subjects in which he acquires knowledge but not necessarily develops thinking skills. Therefore, an important question that arises is at what age should a student be taught thinking skills? Tzohar-Rozen and Kramarski (2013), showed that skills imparted at a young age are 
also applied in adulthood, particularly in matriculation and university exams. Gardner (1983), in his theory of multiple intelligence, claims that every person has eight types of intelligence, some more dominant and some less. He also discovers that all types of intelligence can be developed and improved with appropriate guidance at an early age for any individual based on this theory.

Two questions have engaged many researchers over the years. First, what are the skills and tools that must be imparted to students to develop mathematical and geometric thinking? Second, how can such a process be performed efficiently?

The outcomes following research treating these questions lead to a shift in pedagogic methods. The perception began to permeate among teachers and researchers in education that the transfer of knowledge is not sufficient to develop thinking (Zimmerman, 1990). A more efficient method is imparting learning strategies to a student with self-directed learning (Ben-Eliyau \& Linnenbrink-Gracia, 2015). Self-directed learning refers to creating self-thoughts, feelings, and activities designed to achieve learning goals, such as reading and processing data (Zimmerman, 1990). Educators focus on developing and perfecting learning skills that encourage and contribute to the development of independent learners.

Cultivating metacognitive thinking is the result of increasing the number of strategies available to the student (Kramarski \& Friedman, 2014). Another research indicates that mathematicians are also incorporate in their thought processes metacognitive guidance.

This figure underscores the importance of establishing and cultivating problem-solving strategies in this approach (Carlson \& Bloom, 2005).

In this research, we present how self-guidance in learning with an emphasis on metacognition will improve students' understanding and coping in Euclidean geometry studies in middle schools. This subject was chosen as previous research conducted by the National Network for Measurement and Evaluation in Education in Israel (2007) emphasized that this topic is harder for middle school students than other topics in mathematics. We show that the proposed pedagogic model is robust in any subject one wishes to teach as it requires only minor modifications.

This paper is organized as follows: In Section 2, we explore the academic literature on high-school mathematical pedagogic models that use metacognitive. In Section 3, we present a pedagogic model based on the SRL model with a metacognitive component focusing on teaching geometrically related subjects. In Section 4, we discuss the main pedagogical results arising from the model and the experiment.

\section{Literature Overview}

Geometry is a field of mathematics that studies properties of space that are related to distance, shape, size, and relative position of figures (De Risi, 2015). Geometry has been studied for the last 3000 years and is one of the oldest branches of mathematics. In Israel, geometry studies have become an integral part of the curriculum and play a significant part. The Israeli Ministry of Education sees great importance in building broad infrastructures in mathematics and geometry from an early age. This reality has brought Van Hiele characterized understanding in general, and geometrical-understanding in particular as follows:" A person understands a subject if he can apply it to a situation which he never encountered before and consciously presents the solving process" (Van Hiele, 1999).

Van Hiele (1999) based his theory on five stages of learning shapes and bodies According to his theory, the learner cannot reach a certain stage before mastering the stage before it (Van Hiele, 1999). They showed that a student would not be able to reach the ability to write geometric proof in the absence of one of the following five steps (Van Hiele, 1999): recognition, analysis, ordering, deduction, and regulation. Several studies show that by using the Van Hiele pedagogic model, one directs the student to structured learning integrated building information based on knowledge.

The mathematics curriculum in Israel includes three areas: the numerical field (including statistics and probability), the algebraic field, and the geometric field. This academic program is based on the content learned in the first to the sixth grades. In these grades, there is a shift in the level of understanding and analysis capabilities required of the student. During these years, students are required to reach application, analysis, synthesis, and evaluation gradually.

In the 1980s, metacognition was introduced (Shavelson \& Stern 1981). This approach claims that the following four elements must take place for a learning process to be exhausted and meaningful. First, cognition is all the internal processes of information processing that mediate between the stimulus. The response cognition refers to all the knowledge and information available to the person and the processes in which they were acquired, 
processed, and implemented (Flavell, 1979). These internal processes are thinking, perception, understanding, learning, attention, memory, drawing conclusions, making decisions, and solving problems. Second, motivation is the learner's continuous learning process when there is no external supervision and no rewards or sanctions. Third, metacognition is high-level thinking, the individual's knowledge and awareness of his or her cognitive processes, and the ability to actively direct and monitor them (Flavell, 1987) by building new cognitive skills and thus improving learning achievement (Schraw, 1998). Fourth, context learning is a highly self-directed learner that regulates his behavior according to context, environment, and learning situations.

\subsection{Assimilation of Geometric Language and Study of the Proof Model}

Most of the students in their first year of middle school in Israel arrive without writing a mathematical proof. This is a direct result of the fact that they do not learn how to conceptualize. An experiment done by the Organisation for Economic Co-operation and Development (OECD, 2004) shows that students in their first year of middle school are confronted with forms they are familiar with. At this point, the student must already be writing proof based on a collection of sentences that he needs to understand, remember, and know-how to apply. Elementary school students learn the first and second levels of thinking according to Van Hiele's model. In high school, they have to develop the remaining thinking stages. Geometry studies require a' language' that must be assimilated among students. This language is not only based on a collection of sentences and definitions but also on the ability to construct logical arguments and draw conclusions. In the first phase, the Israeli Ministry of Education, the Division for Curriculum, has built a dictionary of geometry terms that every student should be familiar with during his years of high school. The difficulty the student has to deal with is not necessarily getting familiar with this information, but its application and the way it is formally written. During their studies the students were requested write a proof that requires high-order thinking (Tzohar-Rozen \& Kramarski, 2013).

\subsection{The Effect of Thinking and Intelligence on Learning Processes in Geometry}

Dealing with the definition, statements, and mathematical theorems is relatively easy for students as it only requires memorizing a relatively small collection of data points (Beyer, 2001). The main challenge facing students is the ability to write proofs and develop geometric logical thinking. To assist students in this challenge, two concepts needed first to be defined: thinking and intelligence. These concepts accompany and influence every learning process in general and geometry in particular.

We define thinking as an activity in the brain, which deals with information received from the environment by the senses or extracted from memory and its processing or reorganization. In parallel with the study of thinking, researchers also discuss intelligence, the set of skills that can be used to solve problems requiring thinking. By 1983, there was a widespread belief that there is one general intelligence, and the IQ testhe IQ test assessed it assessed it. Howard Gardner (1996) argued that there is no one general intelligence, but there are multiple intelligences. Two intelligences that are related to the learning process of mathematical subjects are mathematical logical intelligence and geometric intelligence. On the one hand, one may come across a student who demonstrates high abilities in the calculation, inference, the ability to use an algorithm to solve a problem, and on the other hand, has difficulty with visual perception and the ability to abstract. In an innovative and evolving world environment, students are required to solve problems based on a built-in memory process and problem-solving (Paul, 1993).

\subsection{Pedagogic Model}

Self-redirected learning (SRL) has been proven in many fields, including mathematics, to improve achievement and improve learning processes (Pintrich, 2000). We chose to focus on SRL because it is meaningful for both the teacher and the student. SRL provided a solution to developing mathematical thinking skills (Putnam, 1992; Kramarski \& Revach, 2009).

The self-directed meta-cognitive component in the SRL method is significant because it allows the student to realize his potential. During the theoretical learning process, it was found that there is a gap between the level required in the teaching and learning processes and the level of knowledge and abilities of the student. This gap will diminish while improving learning processes that incorporate metacognitive knowledge (Kramarski \& Revach, 2009).

To bridge this gap, one needs to build a uniform learning model that will provide a different solution for each student through this model. Each student will be able to reduce the gap in comparison to the official program. In this study, we will present a model that will guide students in developing learning skills in geometry. This intention will contribute to the development of levels of thinking according to the Van Hiele theory.

The proposed pedagogic model is based on the model proposed by Mevrach et al. and Michalsky (Mvarech \& Kramarski, 1997; Michalsky, 2013). Our model enhances their model by introducing the self-directed 
meta-cognitive component specifically for the development of geometric thinking.

\section{Experiment}

\subsection{Methodology}

The research population included 21 ninth-grade students in middle school in Israel. At the beginning of the academic semester, the classroom teacher provided the students with a questioner (see Table 1) with a rhetorical question based on the proposed metacognitive model. Also, the classroom mathematics teacher was provided with the following guideline. First, students should be trained based on the questioner they have been provided with. They should be encouraged to practice mathematics based on the metacognitive model in both the classroom and home. Second, the construction of a question should be performed mainly in the practice stages of the lesson. They should encourage students to practice writing styles that develop mathematical thinking processes and not just memorization. Third, based on the idea that the right mathematical in general and geometric are structured from rules and laws that include information, prior knowledge, and logic. Students must be trained to use these rules and laws in the correct form of mathematical language. Table 1 showed that line of questions for the high school students.

Table 1. The questionnaire provided to the high-school students

\begin{tabular}{|c|c|c|}
\hline $\begin{array}{l}\text { Question } \\
\text { Symbol }\end{array}$ & Question & Type \\
\hline Q1 & What is the exercise about? Is all the data clear? Mark or explain in words what does each figure mean? & Understanding \\
\hline Q2 & $\begin{array}{l}\text { Is there prior knowledge that you can use? Discover and locate the hidden data (which is not explicitly given } \\
\text { in the question)? Can they help you? }\end{array}$ & Contact \\
\hline Q3 & $\begin{array}{l}\text { What are the courses of action you will choose in order to solve the problem/write the proof? How do you } \\
\text { build the proof? What sentences will you use? What are the symbols you will use? }\end{array}$ & Strategy \\
\hline Q4 & How do you check that the proof is valid? & Validation \\
\hline Q5 & Are there other ways to prove it? Compare with your classmate. What were the difficulties you encountered? & Self-esteem \\
\hline Q6 & $\begin{array}{l}\text { Build a geometry question based on sentences and information from the above question and let your } \\
\text { classmate solve it. }\end{array}$ & Activation \\
\hline
\end{tabular}

Afterward, the students had ten mathematical lessons (over 8 weeks) based on the proposed model on a new subject that they had not learned before, which was partially based on the last subject they learned. The usage of the model was incorporated during the lessons in the classroom and during the time students perform homework at home. Emphasis was placed on the teacher's assimilation of the proposed model in metacognitive guidance in a systematic and orderly manner.

Finally, after the last lesson, the students were asked to fill out another questionnaire regarding their experience from the previous 10 studies (see Table 2).

\subsection{Research Questions}

The research question we dealt with was the contribution of metacognition guidance to improve learning processes in geometry and develop geometric thinking among ninth-grade students.

\subsection{Data \& Results}

The experiment was conducted on 21 students, six males (28.57\%), and 15 females (71.42\%). All students were nine graders, ages 14 to 15 years old.

Table 2. The questionnaire provided to the high-school students

\begin{tabular}{ll}
\hline Q1 & What is the exercise about? Is all the data clear? Mark or explain in words what does each figure mean. \\
Q2 & Is there prior knowledge that you can use? Discover and locate the hidden data (which is not explicitly given in the question)? \\
Can they help you? & What are the courses of action you will choose in order to solve the problem / write the proof? How do you build the proof? \\
Q3 & What sentences will you use? What are the symbols you will use? \\
Q4 & How do you check that the proof is valid? \\
Q5 & Are there other ways to prove it? Compare with your classmate. What were the difficulties you encountered? \\
Q6 & Build a geometry question based on sentences and information from the above question and let your classmate solve it. \\
Q7 & Build a geometry question based on sentences and information from the above question and let your classmate solve it. \\
Q8 & Build a geometry question based on sentences and information from the above question and let your classmate solve it.
\end{tabular}


The study was conducted following the approval given by the Office of the Chief Scientist in the Ministry of Education in the State of Israel in two Israeli high-schools.

Figure 1 below shows the students' histogram answers for the self-examination questionnaire filled out after the last lesson. The x-axis is the questions' index in the questionnaire and the y-axis is the percent of students who chose each of the five available answers (where 1 is "I fully disagree" and 5 is "I fully agree"-ranging from 1 to 5 according to the Likert scale). Where each answer is presented in a different color from right to left, respectively. The reliability of the questionnaire is 0.804 in the Alpha Cronbach index.

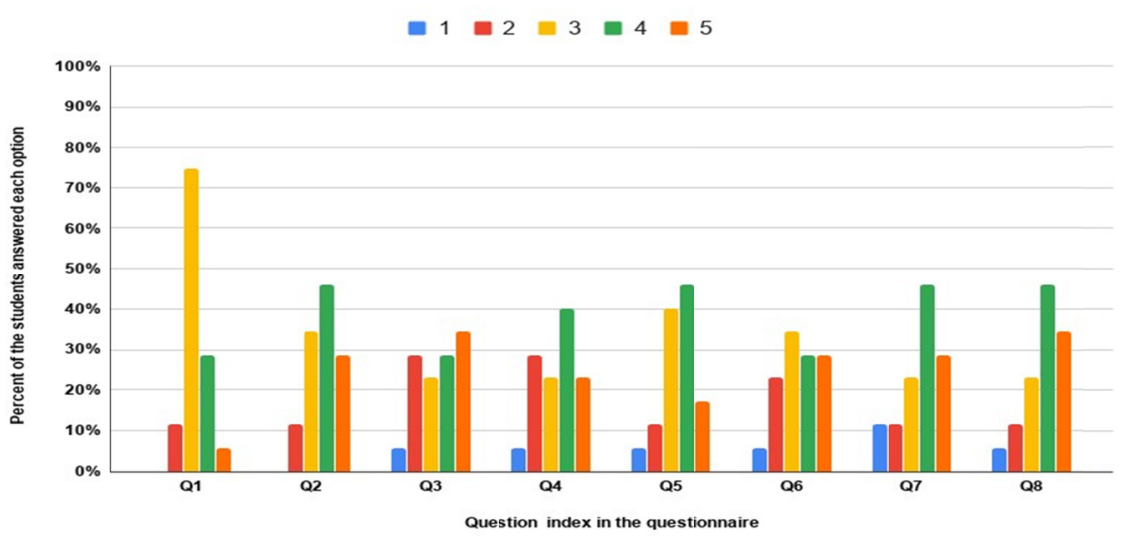

Figure 1. Histogram of students' answers for the self-examination questionnaire filled out after the last lesson. For the complete questions, see Table 2

\section{Discussion}

Students improve their thinking processes and analytical skills via mathematics studies (Gravemeijer \& Erede, 2009). This is true for the study of mathematics in general and applied to the study of geometry in particular. In geometry studies, the student must have advanced thinking skills compared to the average level of middle school. Besides, students are required to combine logic with the reasoning in a formal mathematical framework. When a student is lacking one of them, the student can not build the proof.

We have presented a model based on questions aiming to help a middle school teacher design lessons with meta-cognitive guidance. This model provides a three-point solution using metacognition. First, the awareness of what

the learner knows (metacognitive knowledge). Second, what the learner can do (metacognitive skills). Third, the cognitive abilities of the learner (metacognitive experience). On the one hand, the model allows the learner to be independent and design for himself the learning process. On the other hand, the model allows students to perform effective collaborative learning with their classmates by constructing questions relevant to the learner (Dillon, 1982).

The experiment results show that $90.47 \%$ of the question sheet prepared for the students helped them understand the topic being studied in the self-declare of model usefulness by $n=10$ students. Besides, it was found that the model contributed to students' understanding of the latest data they studied as declared by $85.71 \%$ of the students. The connection of the subject that was studied to prior knowledge is very significant in the study of geometry since without connection to prior knowledge, the student will not understand the context. $71.42 \%$ of students declared that the questions helped them connect the subject being studied to subjects studied and write a mathematical proof.

The amount of different middle school geometry concepts is relatively significant as it includes many definitions, axioms, and theorems. In geometry studies, a student must have a deep understanding of the concepts, and $85.71 \%$ of the students declared that the proposed model helped them understand the concepts better. In an innovative and evolving environment, students are required to solve problems based on a built-in memory process and solve problems that they did not see before. $76.19 \%$ of the students declared that the model helped them solve complex, unfamiliar, and unconventional problems. 
Students declared positive improvements after just two months of learning with the proposed model, as shown in Figure 1. Specifically, both the average and median values are higher than three, which shows that on average, students benefit from using the original pedagogical model used in Israel in 2020. Nevertheless, we argue that complementary research needs to be conducted to better understand the proposed model's pedagogical implications. First, the model should be implemented for metacognitive guidance in middle schools as part of a routine learning process and examine changes in students' performance in a long-time study. Second, a professional development course for teachers should be conducted on the intelligent use of the metacognitive guidance model and its contribution to the learning system and examine changes in their students' performance. Finally, we request to examine the effectiveness of metacognitive guidance and its contribution to online learning. This study presents the contribution of metacognitive orientation in the study of geometry. The pedagogical model can be integrated with other interrelated areas such as science, technology, and mathematics (STEM) and thus contribute to interdisciplinary learning.

\section{Recommendations}

1) A longitudinal study with a larger number of participants should be conducted to contribute to the "model" to increase the number of students in five units of mathematics.

2) Examine whether students will use the "model" in other mathematics study topics.

3) Practical mathematics curricula should be built that incorporate meta-cognition.

4) A personal curriculum for each student based on the "model" should be built, thus reducing learning gaps and improving students' academic achievement in geometry.

5) Further research should be conducted to examine the extent to which the "model" contributes to reducing anxiety about studying mathematics in general and geometry in particular among students.

\section{References}

Ball, D. L. (1990). Prospective elementary and secondary teachers understanding of division. Journal for Research in Mathematics Education, 21(2), 132-144. https://doi.org/10.2307/749140

Ball, D. L. (1996). Teacher learning and the mathematics reform: What we think we know and what we need to learn. Phi Delta Kappa, 500-508.

Ben-Eliyau, A., \& Linnebrink-Gracia, L. (2015). Integrating the regulation of affect, behavior, and cognition into self-regulated learning paradigms among secondary and post-secondary students. Metacognition and Learning, 10(1), 15-42. https://doi.org/10.1007/s11409-014-9129-8

Beyer, B. K. (2001). What Research Says About Teaching Thinking Skills. In A. L. Costa (Ed.), Developing Minds. A Resource for Teaching Thinking (pp. 275-282).

Carlson, M. P., \& Bloom, I. (2005). The Cyclic Nature of Problem Solving: An Emergent Multidimensional Problem-Solving Framework. Educational Studies in Mathematics, 58, 45-75. https://doi.org/10.1007/s10649-005-0808-x

De Risi, V. (2015). Mathematizing Space: The Objects of Geometry from Antiquity to the Early Modern Age. Birkh"auser.

Flavell, J. H. (1979). Metacognition and cognitive monitoring: A new area of cognitive-developmental inquiry. American Psychological Association, 34(10), 906-911. https://doi.org/10.1037/0003-066X.34.10.906

Flavell, J. H. (1987). Speculations about the nature and development of metacognition. In F. Weinert \& R. Kluwe (Eds.), Metacognition, Motivation, and Understanding (pp. 21-29). Erlbaum, Hillsdale, NJ.

Gardner, H. (1983). Frames of Mind. New York. Basic books.

Gravemeijer, K., \& Van Erede, D. (2009). Design Research as a Means for Building a Knowledge Base for Teachers and Teaching in Mathematics Education. Eindhoven University of Technology Utrecht University. https://doi.org/10.1086/596999

Kramarski, B., \& Friedman, S. (2014). Solicited versus Unsolicited Metacognitive Prompts for Fostering Mathematical Problem-Solving Using Multimedia. Journal of Educational Computing Research, 50(3), 285-314. https://doi.org/10.2190/EC.50.3.a

Kramarski, B., \& Revach, T. (2009). The challenge of self-regulated learning in mathematics teachers professional training. Educational Studies in Mathematics, 72, 379-399. https://doi.org/10.1007/s10649-009-9204-2 
Leviathan, T. (2012). The basics of mathematical thinking. Mofet Institution.

Michalsky, T. (2013). Shaping self-regulation in science teachers professional growth: Inquiry skills. Science Education, 96(6), 1106-1133. https://doi.org/10.1002/sce.21029

Michalsky, T., \& Kramarski, B. (2008). Cultivating self-directed learning in instructional flowers in an online environment is connected to the concept of teaching and learning (pp. 765-798).

OECD. (2004). Organisation for Economic Co-operation and Development.

Paul, J. R., Gregory, W. S., Elizabeth, M. H., \& Karen, M. F. (2015). The Language of Mathematics: The Importance of Teaching and Learning Mathematical Vocabulary (pp. 235-252). https://doi.org/10.1080/10573569.2015.1030995

Paul, R. (1993). Critical Thinking: How to Prepare Students for a Rapidly Changing World (pp. 276-277).

Perry, N. E., Phillips, L., \& Hutchinson, L. (2006). Mentoring student teachers to support self-regulated learning. The Elementary School Journal, 106(3), 237-254. https://doi.org/10.1086/501485

Pintrich, P. R. (2000). The role of goal orientation in self-regulated learning. The University of Michigan, Ann Arbor. Handbook of Self-Regulation, 451-529. https://doi.org/10.1016/B978-012109890-2/50043-3

Putnam, R. T. (1992). Teaching mathematics for understanding: discussing case studies of four 5th-grade teachers. Elementary School Journal, 93(2), 213-228. https://doi.org/10.1086/461723

Schraw, G. (1998). Promoting general metacognitive awareness (pp. 113-125). Department of Educational Psychology. Instructional Science, Kluwer Academic Publishers.

Shavelson, R. J., \& Stern, P. (1981). Research on Teachers' Pedagogical Thoughts, Judgments, Decisions, and Behavior. Review of Educational Research, 51(4), 455-498. https://doi.org/10.3102/00346543051004455

The National Network for Measurement and Evaluation in Education in Israel. (2007). Achievements of students in Israel in the Timss test in mathematics. Retrieved from https://cms.education.gov.il/EducationCMS/Units/Rama/MivchanimBenLeumiyim/TIMSS+2007.htm

Tzohar-Rozen, M., \& Kramarski, B. (2013). How can an affective self-regulation program promote mathematical literacy in young students? Hellenic Journal of Psychology, 211-234.

Van Hiele, P. M. (1999). Developing geometric thinking through activities that begin with play. Teaching Children Mathematics, 5(6), 310-316. https://doi.org/10.5951/TCM.5.6.0310

Zimmerman, B. J. (1990). Self-regulated learning and academic achievement: An overview. Educational Psychology, 25(1), 3-17. https://doi.org/10.1207/s15326985ep2501_2

\section{Copyrights}

Copyright for this article is retained by the author, with first publication rights granted to the journal.

This is an open-access article distributed under the terms and conditions of the Creative Commons Attribution license (http://creativecommons.org/licenses/by/4.0/). 